\title{
An Introduction to Security-Classified Libraries for Universities
}

Mr. Fry is chief librarian, Technical Information Service, Atomic Energy Commission, Washington, D.C.

$\mathrm{T}$ HIS PORTION of the study of technical reports deals solely with problems which face the university library in establishing and servicing a security-classified reports collection. There are notable differences in methods and procedures employed in operating an open, unclassified research library and a security-classified library whose materials and access are rigidly controlled in the interests of national defense.

The atmosphere of secrecy and security appeared on many university campuses during the last war, when the government poured immense sums of money into scientific research. Under the Office of Scientific Research and Development defense-related research contracts were written with numerous universities and research institutionsmost of which were carried out in secrecy, with precautions about compartmentalization of information and clearance of individuals accepted as normal conditions of work. For the most part the needs for library service of these secret project groups were met with little difficulty by university libraries and involved mainly a heavy demand for journals and translations. No classified technical report collections of any size were then in existence.

One of the first security-classified libraries was set up in 1942 on the University of Chicago campus by the so-called Metal-

${ }_{1}^{1}$ Paper presented before the meeting of the University Libraries Section, ACRL, Chicago, January $30,1952$. lurgical Laboratory under the Army's Manhattan (atomic bomb) Project at the university. It included both journal and book publications from the university library, and a small but rapidly growing classified report collection. The library staff of the Metallurgical Laboratory, headed by Herman H. Fussler, pioneered in developing bibliographic machinery for the dissemination and control of securityclassified technical information. A direct descendant of this library flourishes today at the Argonne National Laboratory, a few miles out of Chicago, now operated by the university for the Atomic Energy Commission. Other early classified collections were established during the war at Columbia, Harvard, Cornell, Rochester, California and other institutions.

Since the end of World War II, we have been engaged in a world-wide conflict which takes on all the aspects of war except the formal declaration and which involves measures depending upon secrecy for their maximum effect. Our government has placed an increasing importance upon the role of scientific research in defense activities. The contract type of research and development operation with universities has been expanded enormously in recent years. A substantial percentage of these defenserelated research projects are carried out under conditions of security and secrecy. The rapid growth and expansion of research during and since the war has brought a flood of documents and the rise in importance of the technical report. Of the estimated 150,000 or more technical reports 
being produced annually, perhaps $60 \%$ are under security restrictions, and consequently conventional journals are automatically ruled out as media of publication. Security considerations of compartmentalization have limited the development of analogous classified journals to a few specific, clearly defined areas. In the main, therefore, collections of classified materials are composed of separate technical reports.

Before proceeding further with discussion of security problems in library handling of technical reports, it is necessary to define terms which may be unfamiliar to many university librarians. First of all, the word "security," as used here, generally means safeguarding and protection of classified documents against unlawful dissemination, duplication, or observation because of their importance to national defense. The terms "classified" and "classification," apart from their meaning in standard library usage, refer to degrees of secrecy which prevent disclosure to unauthorized persons. Each document is security-classified individually, subject to future change or declassification. The four gradations of classification in descending order of importance to national security are "top secret," "secret," "confidential," and "restricted." Definitions of these four categories, together with numerous other terms which have specific application to security-classified information, may be found in the Federal Register under Executive Order 10290, issued on September 27, 195I, titled "Minimum Standards for the Classification, Transmission and Handling . . . of Official Information Which Requires Safeguarding in the Interest of the United States."

Two additional terms which have an importance to this discussion are "clearance" and "compartmentalization." The granting of "clearance" to an individual simply means it has been determined, by investigating the past history of a person, that he is sufficiently trustworthy to be given access to security-classified information. "Compartmentalization" is the "need to know," based on the principle that a person should have access to only as much information as may be necessary for his particular job. This principle is a central feature of much classified library administration and will be expanded upon later in this paper.

Government regulations covering the control of security-classified documents are found in the several manuals prepared by the Defense Agencies and the Atomic Energy Commission. These manuals are sometimes issued as unclassified and made publicly available through the Government Printing Office. For example, you can obtain for ro cents a copy of the Department of Defense pamphlet titled "How to be Cleared for Handling Classified Military Information Within Industry." Other manuals or regulations which are "restricted" can be obtained from the issuing agency only on a basis of authorized or contractual interest. A librarian can inform himself on most of the basic security requirements of government agencies by reading the Executive Order on "Minimum Standards," referred to above.

The participation of the university library in providing library services to a security-classified research project on the campus will, of course, be determined by the type and scope of contract entered into by the university. In the past, librarians have seldom been drawn into the planning and organization of their universities' contract-supported research programs, particularly in classified areas, and have not been able to make their libraries as useful as they might have been. What is needed is for the librarian to impress upon the administrative officers of the university the services that can usefully be provided by libraries as direct parts of the contracts 
themselves, or even under separate contracts. This is especially necessary where classified research work is involved, because contracting officials must keep to a minimum the number of people cleared and authorized access to classified information.

Government research projects undertaken by a university may be described administratively under one of the following categories:

I. A department of research administration set up to arrange and direct all contractual activities of the university.

2. Separate research projects, ranging in scope from an individual scientist to one or more departments.

3. Government-owned facilities, operated and manned by a university or by a group of universities.

By familiarizing himself with the scope and content of his institution's contractsupported research program, the librarian can make known to the administration whether the library can make a useful contribution to a particular project. If the contribution is expected to be substantial either in terms of staff or services, the library is usually allotted an appropriate part of the overhead allowance.

Inefficiency in the use of the available technical information, or lack of information, impairs the effectiveness of an entire research organization. This possibility is inherent in a classified research program because of security restrictions upon the flow and interchange of information. Thus, it becomes doubly important to the scientist on classified work that he enlist the aid of the university library in utilizing all literature resources available to him, particularly in the field of classified technical reports. If properly cleared and oriented into the nature of the project, the librarian can bring to bear upon the scientist's research problem the bibliographical expertness which is needed to obtain the more elusive laboratory reports, translations, conference minutes and other pertinent technical documents not normally available through routine acquisition channels. The identification and location of technical reports is a notoriously difficult job even when a project is serviced by one of the centralized agencies for handling and controlling technical reports. Special bibliographical jobs will also need to be done locally. In addition, a positive, aggressive program tor acquisition of documentary materials should be developed to obtain reports useful to the research project, but which might not be supplied by the agency sponsoring the contract. Accession lists, abstract journals, and other guides to reports received and produced by other government agencies should be regularly scanned for project use.

Government agencies which sponsor the majority of contract research projects have established central documentation services which control bibliographically the large part of the technical report literature, both classified and unclassified, produced by defense-related research programs. These documentation centers include the Navy Research Section of the Library of Congress, the Central Air Documents Office at Wright-Patterson Field, the Division of Research Information of the National Advisory Committee for Aeronautics, and the Technical Information Service of the Atomic Energy Commission. (The Navy Research Section and the Central Air Documents Office have recently been integrated under a single Armed Services Technical Information Agency.) These documentation centers provide their own agency laboratories and contractors with technical information services in all security classifications. They collect and distribute reports, make and distribute abstracts and catalog cards, and prepare bibliographies for those requesting them. 
Several universities now operate through their defense-related research projects large, organized collections of classified and unclassified reports. Although such projects are under university contract, they tend to become separate organizations for operational purposes, with separate library service distinct from the university library system.

The greatest opportunity for service by the university library lies with the numerous small contract research projects on the campus. The number of these may be quite large and may represent several Defense agencies, e.g., Atomic Energy Commission, Office of Naval Research, Bureat of Ships, Air Force Research and Development Command, Army Chemical Corps, Army Ordnance, etc. There is need here for central bibliographical assistance and coordination of service which the university library can perform. At present, much duplication may be involved, with each research project receiving separately catalog cards and reports in related fields. With the establishment of the Armed Services Technical Information Agency, it is probable that hereafter only one security clearance and one set of security regulations will be required for handling classified technical information on behalf of contractors of all agencies of the Defense Department. Separate clearances are required for classified projects sponsored by the Atomic Energy Commission.

A possible way for the university library to provide technical report service to research contracts, both security-classified and unclassified, would be to establish a classified report collection with facilities and staff personnel cleared to handle military security classifications of "restricted" and "confidential." It would not be feasible under present security regulations for a university classified reports library to provide multiagency service on "secret" and "top secret" reports. It is known that the majority of basic research contracts are classified no higher than "confidential." Within the limits of "restricted" and "confidential" classifications, it could be demonstrated that participation of the university library would advance research and at the same time provide for classified reports stronger security protection than the individual scientist operating by himself can give. The librarian is oriented, trained, and experienced in record keeping and bibliographical control, which uniquely qualify him for the exacting job of safeguarding classified documents.

The experience of most agencies and institutions operating classified report libraries has evolved two successful methods for the administration and housing of a complete library service. One plan is to set up two physically separate library collections, one containing classified reports, the other unclassified reports, books and periodicals. Each is independently staffed and served by separate catalogs and bibliographical tools. The advantages of this type of organization are that it permits access to the open literature section by uncleared personnel and presents fewer security problems in terms of staffing and physical protection. It has the disadvantages of lack of integration of reference service across classification lines and some duplication in processing and service functions.

The other type of approach to the problem of housing and servicing a classified collection is to combine the two collections physically and administratively, to provide an integrated reference service.

In both cases separate catalogs are usually maintained because interfiling of subject headings for books and reports is not possible without extensive re-working. Also, it is necessary in both cases to observe such rules of compartmentalization as may apply, usually on the basis of a subject category access authorization. "Need to know" is a meaningful criterion only when classified 
reports can be furnished in terms of definite control factors: (I) Specific reports (2) Series or categories of reports (3) Contract source (4) Sponsoring agency (5) Classification (6) Physical areas or degrees of security clearance.

Requirements for safe storage of classified documents may be found described in detail in the Executive Order on Minimum Standards, referred to above, and need not be considered here. Cataloging, filing and arrangement of classified reports ordinarily present no unique security problems and likewise are not discussed in this paper.

The maintenance of adequate records and control procedures on security-classified reports is an operational problem of the greatest importance. Lax security handling involving compromise of classified information can have serious consequences. Good security can be maintained by means of simple, effective procedures, plus constant vigilance. The basic control record is a permanent accession record identifying and showing the ultimate disposition of all classified reports received and distributed. It is essential this record give evidence of internal completeness. In addition to the accession or "log" record, a 2-3-4-copy receipt is used to show transfer of accountability when a classified report changes hands. Receipts are usually optional for the "restricted" and "confidential" classifications, but are mandatory for "secret" and "top secret." For internal circulation, some classified report libraries use the standard $3^{\prime \prime} \times 5^{\prime \prime}$ library book card to record the temporary holder of the document. At some time or other most classified report libraries are required to take an inventory or to make a spot check of their holdings in order to determine whether any reports are missing, to assess security deficiencies, and also to evaluate the adequacy of their record controls.

For the sake of brevity and simplicity it has been necessary in several instances to make statements which for complete accuracy would require much greater qualification and elaboration than there is time to give them. In addition, there are many problems deserving more attention and fuller treatment. The need to reconcile maximum dissemination with adequate security control has required the development of many new procedures and the application of library principles and techniques to new and highly specialized material.

\section{Periodical Binding Schedules (Continued from page 226)}

bination of both. Eighty-three per cent of libraries reporting either had no campus bindery available or could not have all binding done on the campus. Those libraries following binding schedules based on reader service, as well as those with no organized plan had access to campus facilities in the same proportion as the total reporting. Analysis indicated that the location of the bindery is not a factor in the formulation of binding schedules based on reader demand. Also in the opinion of the majority of libraries reporting, the location of the bindery could not of itself contribute to the effectiveness of a schedule aimed at improved reader service.

\section{Conclusion}

This paper suggests specific procedures for developing serials binding schedules to minimize disruption in service to readers. Ideally such scheduling should be controlled by those who have first-hand knowledge of reader demand. Adoption of these or other specific techniques can be expected to improve reader service generally. 